\title{
TSLP promotes angiogenesis of human umbilical vein endothelial cells by strengthening the crosstalk between cervical cancer cells and eosinophils
}

\author{
BING ZHANG $^{1,2^{*}}$, CHUN-YAN WEI $^{1 *}$, KAI-KAI CHANG ${ }^{1}$, JIA-JUN YU $^{1}$, WEN-JIE ZHOU ${ }^{1}$, \\ HUI-LI YANG ${ }^{1}$, JUN SHAO ${ }^{1}$, JIN-JIN YU ${ }^{2}$, MING-QING LI ${ }^{2,3}$ and FENG XIE ${ }^{4}$ \\ ${ }^{1}$ Laboratory for Reproductive Immunology, Hospital of Obstetrics and Gynecology, Fudan University, Shanghai 200011; \\ ${ }^{2}$ Department of Obstetrics and Gynecology, The Affiliated Hospital of Jiangnan University, Wuxi, Jiangsu 214062; \\ ${ }^{3}$ Shanghai Key Laboratory of Female Reproductive Endocrine Related Diseases; ${ }^{4}$ Medical Center of Diagnosis and \\ Treatment for Cervical Diseases, Hospital of Obstetrics and Gynecology, Fudan University, Shanghai 200011, P.R. China
}

Received March 4, 2016; Accepted July 20, 2017

DOI: $10.3892 / \mathrm{ol} .2017 .7121$

\begin{abstract}
Our previous study demonstrated that thymic stromal lymphopoietin (TSLP) secreted by cervical cancer cells promotes angiogenesis and recruitment, and regulates the function of eosinophils (EOS). However, the function of TSLP in the crosstalk between EOS and vascular endothelial cells in cancer lesions remains unknown. The aim of the present study was to investigate the effect of EOS caused by TSLP in in vitro angiogenesis of human umbilical vein endothelial cells (HUVECs). The results of the present study revealed that recombinant human TSLP protein (rhTSLP) increased the secretion of vascular endothelial growth factor (VEGF), but not fibroblast growth factors, in HL-60-eosinophils (HL-60E). Compared with cervical cancer cells (HeLa or CasKi cells) or HL-60E alone, there were increased levels of interleukin (IL)- 8 and VEGF in the co-culture system between cervical cancer cells, and HL-60E cells. This effect was strengthened by rhTSLP, but inhibited by inhibiting the TSLP signal with anti-human TSLP or TSLP receptor neutralizing antibodies. The results of the tube formation assays revealed that treatment
\end{abstract}

Correspondence to: Professor Feng Xie, Medical Center of Diagnosis and Treatment for Cervical Diseases, Hospital of Obstetrics and Gynecology, Fudan University, 419 Fangxie Road, Shanghai 200011, P.R. China

E-mail: ylxiefeng@163.com

Dr Kai-Kai Chang, Laboratory for Reproductive Immunology, Hospital of Obstetrics and Gynecology, Fudan University, 413 Zhaozhou Road, Shanghai 200011, P.R. China

E-mail: kchang11@fudan.edu.cn

${ }^{*}$ Contributed equally

Key words: thymic stromal lymphopoietin, cervical cancer cells, eosinophils, angiogenesis, interleukin 8, vascular endothelial growth factor with the supernatant from cervical cancer cells and/or HL-60E resulted in an increase in angiogenesis in HUVECs, which could be decreased by TSLP or TSLPR inhibitors. The results of the present study suggested that TSLP derived of cervical cancer cells may indirectly stimulate angiogenesis of HUVECs, by upregulating IL-8 and VEGF production, in a co-culture model between cervical cancer cells and EOS, therefore promoting the development of cervical cancer.

\section{Introduction}

Cervical cancer is one of the most common types of gynecological malignancy with high morbidity and mortality, and seriously affects the living quality of females worldwide (1). The pathogenesis of cervical cancer remains unknown and may be connected with numerous factors (e.g. recurrent genetic alterations, microenvironment and lifestyle) $(2,3)$. According to the latest Cancer Statistics between 2000 and 2011 in China (4), there were 298,900 new cases of cervical cancer, with $>30,500$ mortalities from the disease.

Angiogenesis is defined as the formation of new blood vessels from pre-existing vessels, and is essential for the delivery of nutrients and oxygen to cells that are distant from existing blood vessels (5). Physiological angiogenesis is a sequence of cellular events comprising vascular initiation, formation, maturation, remodeling and regression, which are regulated to supply tissue requirements (5-7). It has been demonstrated that angiogenesis is essential for the growth, metastasis and development of cancer (8). The biochemical stimulation of angiogenesis is induced by angiogenic factors, including vascular endothelial growth factor (VEGF), fibroblast growth factor (FGF), interleukin (IL-)8, angiopoietins, matrix metalloproteinases (MMPs), cadherins and integrins (9-11).

Thymic stromal lymphopoietin (TSLP) is a cytokine produced by stromal cells, epithelial cells, fibroblasts, keratinocytes and basophils (12-14). TSLP triggers T helper 2 cell cytokines, including thymus and activation regulated chemokine, and is associated with airway inflammatory disease, allergic responses, immunoglobulin E production 
and eosinophilia $(12,13,15)$. The TSLP receptor (TSLPR) is a typical heterodimeric cytokine receptor consisting of a TSLP binding subunit (TSLPR $\alpha$ ) and the $\alpha$-subunit of the IL-7 receptor (IL-7R $\alpha)(16,17)$. Our previous study demonstrated that TSLP secreted by cervical cancer cells promotes angiogenesis (18). In addition, an increased level of TSLP in cancer lesions, mediated by hypoxia, was a regulator of the progression of cervical cancer, and functioned by recruiting and enabling tumor-associated eosinophils (EOS) to promote the growth of the cervical cancer cells (19). However, it remains unknown whether and how TSLP, derived from cervical cells, regulates angiogenesis by modulating the crosstalk between cervical cancer cells and EOS. Therefore, the aim of the present study was to investigate the effect of TSLP on the secretion of angiogenic factors VEGF, FGF and IL-8 from EOS, and cervical cancer cells, and on the angiogenesis of human umbilical vein endothelial cells (HUVECs) in vitro.

\section{Materials and methods}

Cell culture. Cervical epidermoid carcinoma HeLa and CasKi cells (Type Culture Collection of the Chinese Academy of Sciences, Shanghai, China) were cultured in RPMI-1640 medium (Gibco; Thermo Fisher Scientific, Inc., Waltham, MA, USA) supplemented with 5\% fetal bovine serum (FBS; Hyclone; GE Healthcare Life Sciences, Logan, UT, USA).

HL-60 cells, a promyelocytic leukemia cell line, were purchased from the Type Culture Collection of the Chinese Academy of Sciences. According to a previous study (19), the HL-60-eosinophils (HL-60E) were generated by incubating HL-60 cells for 2 months at pH 7.7 in RPMI-1640 medium containing $25 \mathrm{mM} \mathrm{N}$-(2-hydroxyethyl) piperazine-N'-3-propane-sulfonic acid (Sigma-Aldrich; Merck KGaA, Darmstadt, Germany) and subsequently culturing for 7 days in RPMI-1640 medium with $0.5 \mathrm{mM}$ butyric acid (Sigma-Aldrich; Merck KGaA). HUVECs (Type Culture Collection of the Chinese Academy of Sciences) were maintained as monolayers in Dulbecco's modified Eagle medium/F-12 medium (Gibco; Thermo Fisher Scientific, Inc.) supplemented with 10\% FBS. These cells were incubated at $37^{\circ} \mathrm{C}$ in a humidified atmosphere containing $5 \% \mathrm{CO}_{2}$.

Co-culture of HL-6OE with HeLa or CasKi cells. HeLa and CasKi cells $\left(2 \times 10^{5}\right.$ cells/well $)$ were cultured with HL-60E cells $\left(2 \times 10^{5}\right.$ cells/well $)$ in a humidified incubator with $5 \% \mathrm{CO}_{2}$ at $37^{\circ} \mathrm{C}$ for $48 \mathrm{~h}$ and subsequently incubated with or without recombinant human TSLP protein (rhTSLP; $100 \mathrm{ng} / \mathrm{ml}$; R\&D Systems, Inc., Minneapolis, MN, USA), anti-human TSLP or anti-TSLPR neutralizing antibodies ( $\alpha$-TSLP or $\alpha$-TSLPR; $5 \mu \mathrm{g} / \mathrm{ml}$; R\&D Systems, Inc.) in a humidified incubator containing $5 \% \mathrm{CO}_{2}$ at $37^{\circ} \mathrm{C}$ for $48 \mathrm{~h}$, and $1 \% \mathrm{PBS}$, as a negative control. Supernatants of the co-culture system were selected for ELISA analysis or tube formation assay. Each experiment was performed in six parallel wells and repeated five times.

ELISA. HL-60E cells ( $2 \times 10^{5}$ cells/well) were seeded in 24 -well plates and treated with rhTSLP $(1,10$ or $100 \mathrm{ng} / \mathrm{ml})$ or $1 \%$ PBS (negative control) at $37^{\circ} \mathrm{C}$ for $48 \mathrm{~h}$. Subsequently, the cell culture supernatants were harvested, centrifuged at $300 \mathrm{x} g$ at $4^{\circ} \mathrm{C}$ for $10 \mathrm{~min}$ to remove cellular debris and stored at $-80^{\circ} \mathrm{C}$ until use. The secretion level of IL-8, VEGF and FGF was determined using human IL-8 (cat. no. EH005-96), VEGF (cat. no. EH015-96) and FGF (cat. no. EH022-96) ELISA kits (Shanghai ExCell Biology, Inc., Shanghai, China), respectively, according to the manufacturer's protocol. In addition, the protein concentration of the control, 1, 10 and $100 \mathrm{ng} / \mathrm{ml}$ rhTSLP groups was determined and the cytokine level of each group was calculated as the ratio of the cytokine concentration of the supernatant to the protein concentration. The experiment was repeated three times. In addition, the level of IL-8, VEGF and FGF in the supernatants of the co-culture system with HeLa or CasKi cells as described above was determined using ELISA. Each experiment was performed in six parallel wells and repeated five times.

Tube formation assay (Matrigel assay). HUVECs $\left(2 \times 10^{4}\right.$ cells/well) were seeded in 96-well plates on growth factor-reduced Matrigel in RPMI-1640 medium (5\% FBS) with recombinant human VEGF protein $(10 \mathrm{ng} / \mathrm{ml}$; a positive control; R\&D Systems, Inc.). Subsequently, HUVECs were stimulated with the supernatants from HeLa (following treatment with or without $\alpha$-TSLP or $\alpha$-TSLPR as aforementioned), CasKi (following treatment with or without $\alpha$-TSLP or $\alpha$-TSLPR as aforementioned), HL-60E, co-culture of HL-60E and HeLa, or co-culture of HL-60E and CasKi cells; the RPMI-1640 medium with 5\% FBS was used as a negative control. After $16 \mathrm{~h}$, in five randomly chosen optical fields with light microscopy, capillary-like tube formation was quantified by counting the numbers of junctions/enclosed circles (original magnification, x100). Each experiment was performed in six parallel wells and repeated five times.

Statistical analysis. All values are presented as the mean \pm standard error of the mean. The data were analyzed using GraphPad Prism (version 5; GraphPad Software, Inc., La Jolla, CA, USA) by one-way ANOVA using Tukey's post-hoc test. $\mathrm{P}<0.05$ was considered to indicate a statistically significant difference.

\section{Results}

rhTSLP promotes VEGF secretion of HL-60E cells. In order to explore the secretion of TSLP on tumor-associated angiogenic factors from EOS, HL-60E cells were treated with different concentrations of rhTSLP protein for $48 \mathrm{~h}$. As presented in Fig. 1,rhTSLP stimulated the production of VEGF from HL-60E cells in a dose-dependent manner (Fig. 1A; $\mathrm{P}<0.05$ or $\mathrm{P}<0.001$ compared with control). Compared with the control group, there was no significant alteration in the level of FGF secreted from HL-60E following stimulation with rhTSLP (Fig. 1B; P>0.05 compared with control). In addition, the secretion of IL-8 in HL-60E was undetected (data not shown). The results of the present study demonstrated that exogenous TSLP upregulated VEGF secretion of HL-60E cells, and may be involved in the promotion of angiogenesis.

Co-culture of HL-60E with cervical cancer cells increases the production of $I L-8$ and VEGF. In order to imitate the local immune environment, a co-culture system of HL-60E and HeLa or CasKi cells was constructed. As presented, 
A
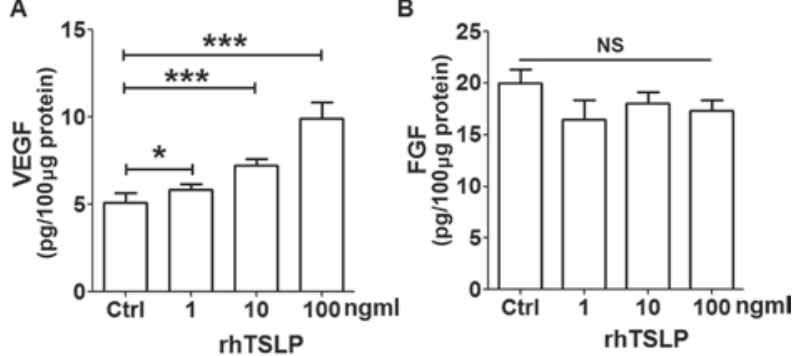

Figure 1. RhTSLP promotes VEGF secretion of HL-60E cells. Following treatment with different concentration of $\operatorname{rhTSLP}(1,10$ and $100 \mathrm{ng} / \mathrm{ml})$ for $48 \mathrm{~h}$, the secretion level of (A) VEGF and (B) FGF was determined in HL-60E cells using ELISA. The data are expressed as the mean \pm standard error of the mean. ${ }^{*} \mathrm{P}<0.05$ or ${ }^{* * *} \mathrm{P}<0.001$ vs. control, determined using one-way analysis of variance. RhTSLP, recombinant human TSLP protein; VEGF, vascular endothelial growth factor; FGF, fibroblast growth factor; NS, no statistical difference.

HeLa or CasKi cells alone secreted an increased level of IL-8 and VEGF compared with that secreted by HL-60E cells alone (Fig. 2A and B). Following co-culture of HL-60E and HeLa, there were increased levels of IL-8 (Fig. 2A; P<0.001 compared with HeLa cells alone or HL-60E alone) and VEGF (Fig. 2B; P<0.01 compared with HeLa cells alone; $\mathrm{P}<0.001$ compared with HL-60E alone), but no change in FGF production (Fig. 2C; P $>0.05$ compared with HeLa cells alone or HL-60E alone). Notably, IL-8, VEGF and FGF levels were increased in co-culture of HL-60E and CasKi cells (Fig. 2; $\mathrm{P}<0.01$ compared with CasKi cells alone for VEGF and FGF; $\mathrm{P}<0.001$ compared with CasKi cells alone for IL-8; $\mathrm{P}<0.001$ compared with HL-60E alone for IL-8 and VEGF). The results of the present study indicated that the interaction between EOS and cervical cancer cells in cancer lesions may involve the secretion of an increased level of tumor-associated angiogenic factors.

TSLP-derived of cervical cancer cells upregulates the secretion of IL-8 and VEGF. To explore whether TSLP secreted by cervical cancer cells is involved in regulating the level of IL-8, VEGF and FGF in a co-culture system, rhTSLP, $\alpha$-TSLP or $\alpha$-TSLPR was added to the co-culture system. As presented, rhTSLP increased IL-8 and VEGF levels in both co-culture systems compared with the control co-culture groups (Fig. 3A and $\mathrm{B} ; \mathrm{P}<0.01$ or $\mathrm{P}<0.001)$. Inhibiting the TSLP signal with $\alpha$-TSLP or $\alpha$-TSLPR resulted in the decreased secretion of IL- 8 and VEGF in the co-culture systems (Fig. $3 \mathrm{~A}$ and $\mathrm{B} ; \mathrm{P}<0.05$ or $\mathrm{P}<0.01)$. However, neither rhTSLP nor TSLP signal inhibitors affected the FGF production in the co-culture system (Fig. 3C; $\mathrm{P}>0.05$ ). These results suggested that endogenous TSLP secreted by cervical cancer cells causes an increased production of angiogenic factors in the co-culture system between cervical cancer cells and EOS.

TSLP stimulates angiogenesis by strengthening the interaction between cervical cancer cells and EOS. To identify the function of cervical cancer cells and EOS in the regulation of angiogenesis in HUVECs, HUVECs were stimulated with the supernatants from HeLa (S-HeLa), CasKi (S-CasKi), HL-60E (S-HL-60E), co-culture of HL-60E and HeLa $(\mathrm{S}-\mathrm{H}+\mathrm{H})$, or co-culture of HL-60E and CasKi $(\mathrm{S}-\mathrm{H}+\mathrm{C})$, and the tube formation of HUVECs were subsequently analyzed. As a positive control, rhVEGF protein significantly stimulated angiogenesis of HUVECs compared with the control (Fig. 4A and B; $\mathrm{P}<0.001$ ). Compared with the control, $\mathrm{S}-\mathrm{HeLa}, \mathrm{S}-\mathrm{CasKi}$ or S-HL-60E resulted in an increase in angiogenesis of HUVECs in vitro (Fig. $4 \mathrm{~A}$ and $\mathrm{B} ; \mathrm{P}<0.05$ ). Compared with S-HeLa, S-CasKi and S-HL-60E alone, $\mathrm{S}-\mathrm{H}+\mathrm{H}$ and $\mathrm{S}-\mathrm{H}+\mathrm{C}$ exhibited a significantly increased stimulatory effect on tube formation of HUVECs (Fig. 4A and B; $\mathrm{P}<0.01$ or $\mathrm{P}<0.001$ ).

Subsequent analysis revealed that these effects may be abrogated by inhibiting TSLP or TSLPR (Fig. 5A and B; $\mathrm{P}<0.01$ compared with control). The results of the present study suggested that the interaction between HL-60E and cervical cancer cells promotes angiogenesis of HUVECs in vitro. Furthermore, TSLP may trigger this process by producing IL-8 and VEGF secretion.

\section{Discussion}

EOS infiltration is a common host response of solid tumors. However, there is no change observed in the number and activation state of peripheral blood EOS (20-22). Ayhan et al (23) demonstrated that between 25 and $100 \%$ of cervical carcinoma tissues contained EOS, and between 2 and $26 \%$ of cervical tumor microenvironments exhibited a significant proportion of EOS infiltration (23). EOS express numerous types of surface functional molecules, including pattern-recognition receptors, siglec-lectin receptors, adhesion molecules, Toll-like receptors, and receptors for cytokines and chemokines $(20,24)$. The expression of these molecules are required for functions in cytotoxic activity via secretory granule proteins, including a matrix composed of eosinophil cationic protein, major basic protein 1 and 2, eosinophil-derived neurotoxin, and eosinophil peroxidase. Three cytokines, IL-3, IL-5 and granulocyte macrophage colony-stimulating factor (GM-CSF), are required for the regulation of EOS development. EOS may be recruited via eosinophil chemokines eotaxin-1 (CCL11), eotaxin-2 and eotaxin-3 $(24,25)$. In the majority of types of solid tumor, EOS tissue infiltration is located in the tumor necrosis area (21). Our previous study revealed that EOS infiltration of the lesion site increased with the progression of cervical cancer (19). TSLP of cervical cancer cells induced by hypoxia was identified to be involved in the recruitment of EOS by stimulating the secretion of chemokine (C-C motif) ligand 17 (19). Previous studies have demonstrated an improved prognosis with tumor-associated tissue eosinophilia (TATE), due to the tumoricidal effects of EOS via degranulation in the local cancer lesions $(26,27)$. However, other studies have suggested that TATE was a poor prognostic indicator in distinct types of solid tumor, including oral squamous cell carcinoma and cervical carcinoma $(19,28)$. Thus, the underlying molecular mechanism of EOS in cancer remains unknown. Previously, we have demonstrated that abnormal increased TSLP in cancer lesions is an important regulator in the progression of cervical cancer, via recruiting and enabling tumor-associated EOS to promote the growth of cervical cancer cells (19).

Blood vessels may serve as a promoter for cancer growth and metastasis by transporting oxygen and nutrients, and removing metabolites (29). Furthermore, in order to 

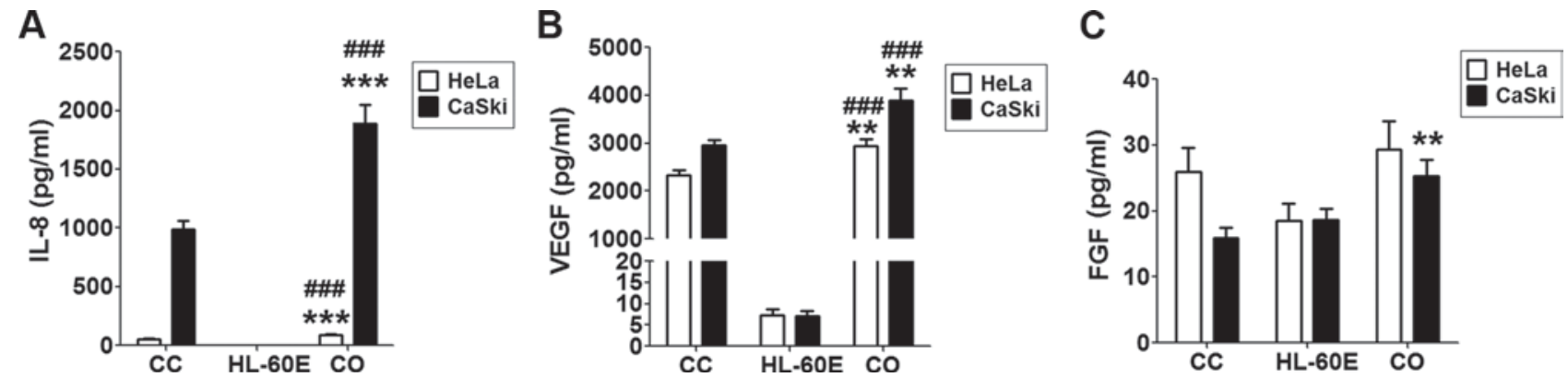

Figure 2. Co-culture of HL-60E with cervical cancer cells increases the production of IL-8 and VEGF. HL-60E were co-cultured with HeLa or CaSki cells for $48 \mathrm{~h}$, and the secretion level of (A) IL-8, (B) VEGF and (C) FGF were analyzed using ELISA. The data are expressed as the mean \pm standard error of the mean. ${ }^{* *} \mathrm{P}<0.01$ or ${ }^{* * * *} \mathrm{P}<0.001$ vs. CC, determined using a one-way analysis of variance; ${ }^{\# \# "} \mathrm{P}<0.001$ vs. HL-60E alone, determined using a one-way analysis of variance. CC, HeLa or CaSki cells alone; HL-60E, HL-60-eosinophils alone; CO, co-culture group of HL-60E with HeLa (black) or CaSki (white) cells; IL, interleukin; VEGF, vascular endothelial growth factor; FGF, fibroblast growth factor.
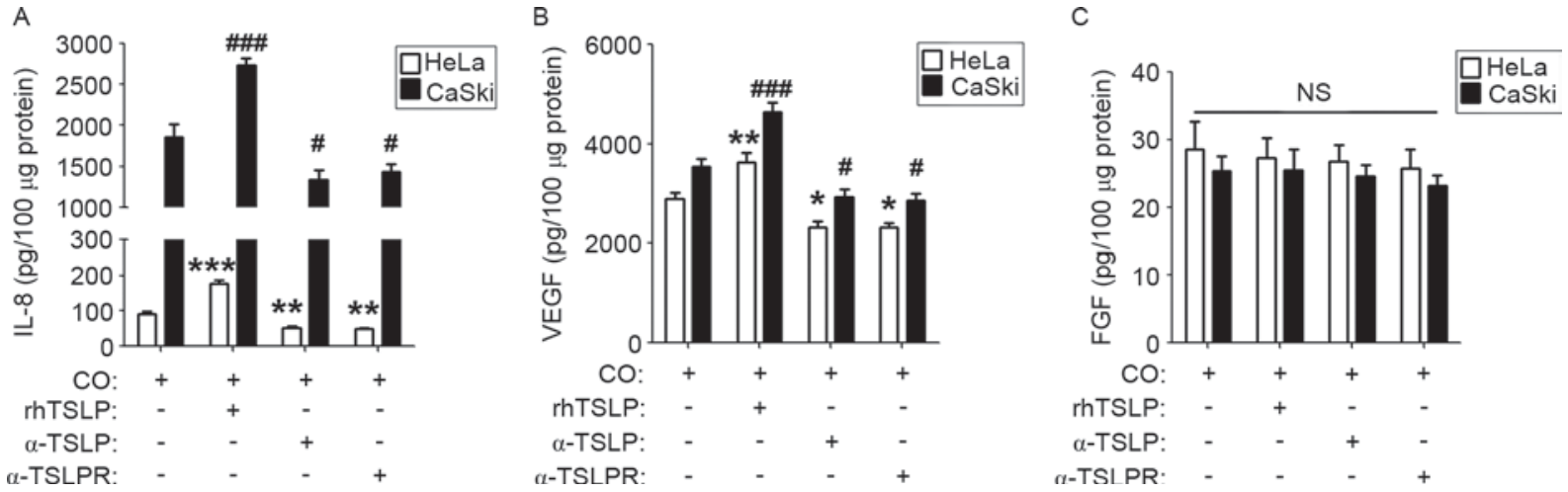

Figure 3. TSLP-derived of cervical cancer cells upregulates the secretion of IL-8 and VEGF. HL-60E were co-cultured with HeLa or CaSki cells for $48 \mathrm{~h}$ and subsequently rhTSLP $(100 \mathrm{ng} / \mathrm{ml}), \alpha$-TSLP $(5 \mathrm{ug} / \mathrm{ml})$ or $\alpha$-TSLPR $(5 \mathrm{ug} / \mathrm{ml})$ was added for an additional $48 \mathrm{~h}$. The secretion level of (A) IL-8, (B) VEGF and (C) FGF were determined using ELISA. The data are expressed as the mean \pm standard error of the mean. ${ }^{*} \mathrm{P}<0.05,{ }^{* *} \mathrm{P}<0.01$ or ${ }^{* * * *} \mathrm{P}<0.001$ vs. CO of $\mathrm{HL}-60 \mathrm{E}$ with HeLa cells control, determined using a one-way analysis of variance; ${ }^{\#} \mathrm{P}<0.05$ or ${ }^{\# \# \# "} \mathrm{P}<0.001$ vs. CO of HL-60E with CasKi cells control, determined using a one-way analysis of variance. CO, co-culture group (HL-60E with HeLa or CaSki cells); TSLP, thymic stromal lymphopoietin; $\alpha$-TSLP, anti-human TSLP neutralizing antibody; $\alpha$-TSLPR, anti-human TSLP receptor neutralizing antibody.
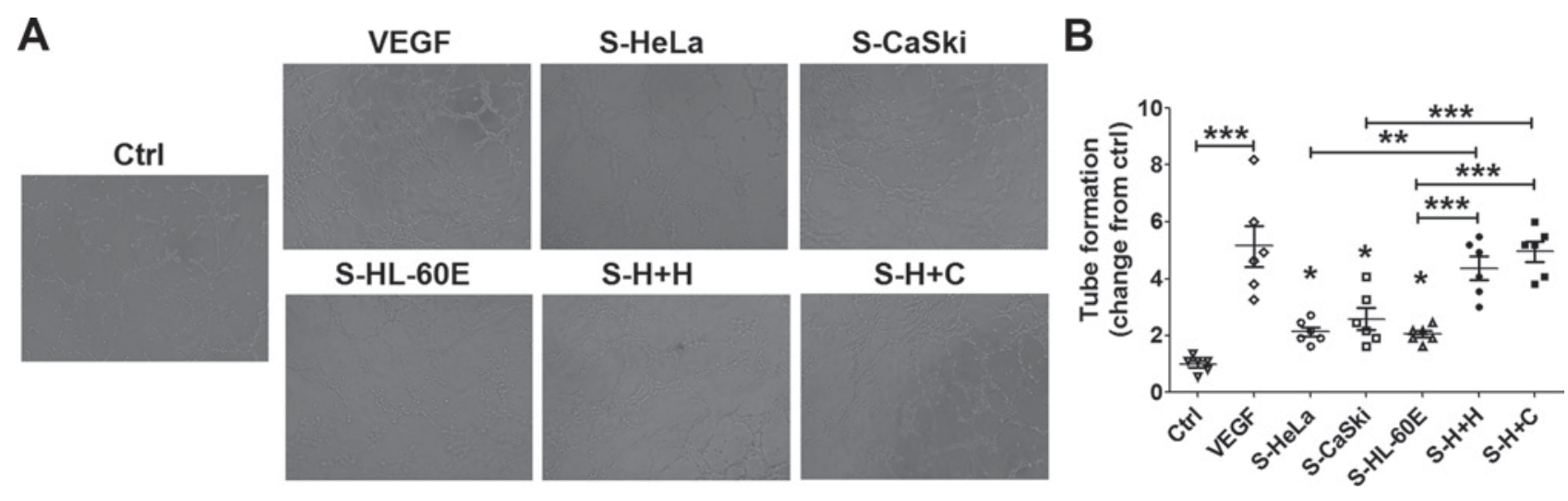

Figure 4. Cervical cancer cells and EOS promotes angiogenesis of HUVECs. (A) HUVECs were treated with the supernatants from HL-60E cells, HeLa, CaSki cells, the culture system of HL-60E cells and HeLa or CaSki cells, or with rhVEGF (10 ng/ml) as the positive control. Original magnification, x100. (B) Subsequently, the tube formation assay was performed to analyze the angiogenesis of HUVECs. The data are expressed as the mean \pm standard error of the mean. ${ }^{*} \mathrm{P}<0.05,{ }^{* *} \mathrm{P}<0.01$ and ${ }^{* * *} \mathrm{P}<0.001$ (one-way analysis of variance). Ctrl, control; RhVEGF, recombinant human VEGF; S-HeLa, the supernatant from HeLa cells; S-CasKi, supernatant from CasKi cells; S-HL-60E, supernatant from HL-60E cells; S-H+H, the supernatant from the co-culture of HL-60E and HeLa cells; S-H+C, supernatant from co-culture of HL-60E and CasKi cells; EOS, eosinophils; rh, recombinant; VEGF, vascular endothelial growth factor; HUVECs, human umbilical vein endothelial cells.

metastasize, cancer cells must invade the tumor-associated neovasculature to obtain access to a distant site in the body (30). Angiogenesis, the formation of new blood vessels from existing ones, is an essential process in physiological 
A
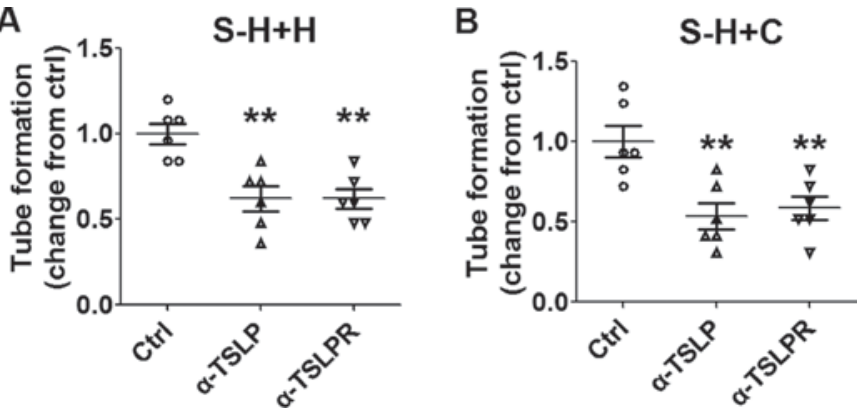

Figure 5. Stimulatory effect of cervical cancer cells and EOS on angiogenesis is dependent on TSLP. Following pre-treatment with $\alpha$-TSLP $(5 \mathrm{ug} / \mathrm{ml}$ ) or $\alpha$-TSLPR $(5 \mathrm{ug} / \mathrm{ml})$ for $48 \mathrm{~h}$, supernatants were selected from the co-culture system of HL-60E with (A) HeLa or (B) CaSki cells. Subsequently, HUVECs were stimulated with these supernatants and angiogenesis was analyzed using a tube formation assay. The data are expressed as the mean \pm standard error of the mean. ${ }^{* *} \mathrm{P}<0.01$ vs. control, using one-way analysis of variance. EOS, eosinophils; Ctrl, control; S-H+H, supernatant of co-culture of HL-60E with HeLa cells; S-H+C, supernatant of co-culture of HL-60E with CaSki cells; EOS, eosinophils; TSLP, thymic stromal lymphopoietin; $\alpha$-TSLP, anti-human TSLP neutralizing antibody; $\alpha$-TSLPR, anti-human TSLP receptor neutralizing antibody; HUVECs, human umbilical vein endothelial cells.

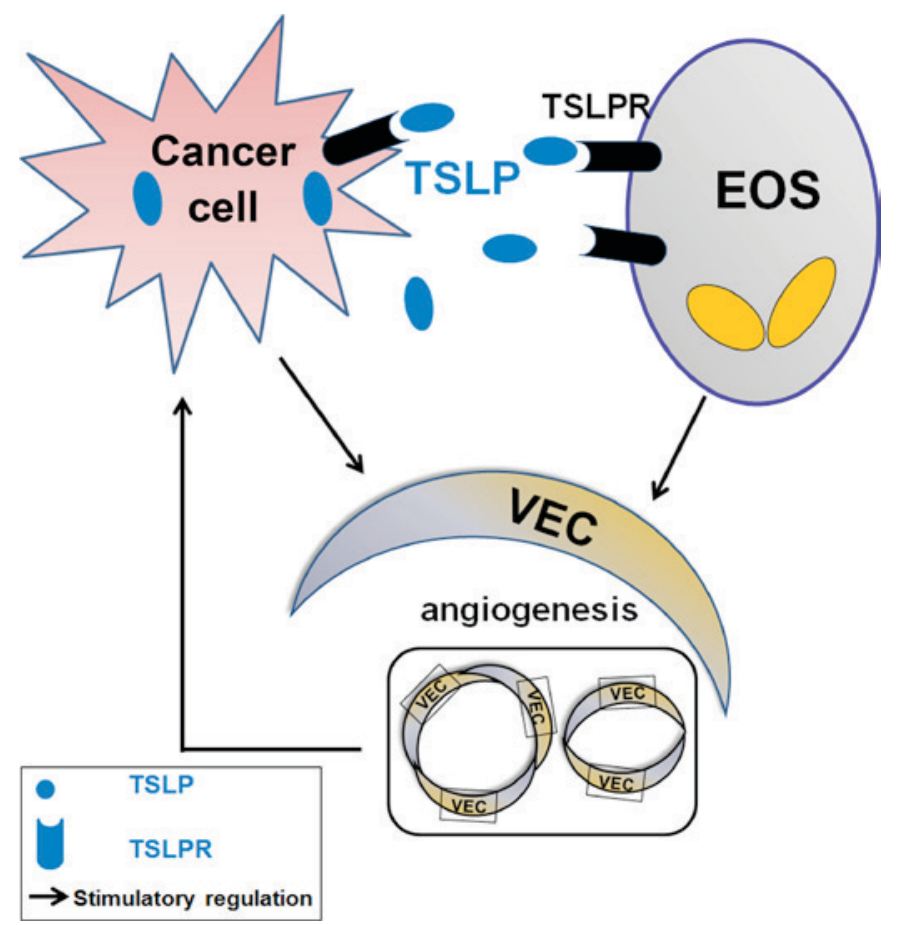

Figure 6. Function of TSLP in angiogenesis by affecting the crosstalk between cervical cancer cells and EOS. Cervical cancer cells secrete an increased level of TSLP. TSLP stimulates the secretion of angiogenic factors (including IL-8 and VEGF) in an autocrine manner; however, TSLP promotes the production of IL-8 and VEGF in a paracrine manner. Together, the dialogue between cervical cancer cells and EOS mediated by TSLP promotes angiogenesis of HUVECs, and thereby accelerates the progress of cervical cancer cells. EOS, eosinophils; TSLPR, thymic stromal lymphopoietin receptor; IL, interleukin; VEGF, vascular endothelial growth factor; VEC, HUVEC; HUVECs, human umbilical vein endothelial cells.

and pathological conditions $(31,32)$. Numerous cytokines, including VEGF, regulate the functions of vascular endothelial cells (32-34). Our previous study demonstrated that cervical cancer cells stimulate angiogenesis of vascular endothelial cells by secreting TSLP (18).
A previous study revealed that the recruitment of EOS to the tumor site may promote angiogenesis and this effect may be induced by VEGF (35). In addition, EOS releases angiogenic factors, including FGF, IL-6, IL-8, GM-CSF, platelet derived factor and transforming growth factor $\beta$ (36). A previous in vivo study demonstrated that EOS-derived CCL11 induced an angiogenic response (37). EOS and tumor associated macrophages accumulated in the hypoxic and/or necrotic areas of mouse subcutaneous B16F10 melanoma, and this process was associated with EOS degranulation (22). These particles of EOS degranulation contain VEGF and other angiogenic factors, which may promote tumor angiogenesis in the hypoxic areas $(38,39)$. In addition, EOS promotes angiogenesis in local cancer lesion by releasing a large number of vasoactive leukotrienes (40). Therefore, in the present study, it was hypothesized that TSLP produced by cervical cancer cells may indirectly regulate angiogenesis by influencing EOS function. The results of the present study demonstrated that rhTSLP treatment significantly upregulated the level of VEGF, but not the FGF level in HL-60E cells in vitro. EOS of peripheral blood could produce IL-8. HL-60E cells did not secrete IL-8. However, HL-60E may promote IL-8 secretion from HeLa or CasKi cells. Following the co-culture of HL-60E cells with HeLa or CasKi cells, the secretion level of IL-8 and VEGF was significantly increased, and this effect was upregulated and inhibited by rhTSLP, and TSLP signal inhibitors, respectively. The results of the present study suggested that TSLP results in an increased level of angiogenic factors through promoting the interaction between EOS and cervical cancer cells.

Subsequent analysis revealed that cervical cancer cells (HeLa or CasKi) and EOS promoted the angiogenesis of HUVECs in vitro, in particular following the co-culture of cervical cancer cells and EOS. However, these effects were inhibited by suppressing TSLP or TSLPR by $\alpha$-TSLP or $\alpha$-TSLPR, respectively, which supported our hypothesis.

The present study demonstrated that TSLP derived from cervical cancer cells promotes the secretion of VEGF of EOS by binding TSLPR and increases the levels of angiogenic factors (IL-8 and VEGF) in the co-culture system by stimulating the interaction between cervical cancer cells and EOS (Fig. 6). The effects of TSLP on cervical cells and EOS may result in the increase of tumor angiogenesis, and contribute to the development and progression of cervical cancer. The results of the present study further the understanding of the biological function of EOS in cancer progression. However, the molecular exact mechanism underlying the effects of TSLP on the level of angiogenic factors secreted from cervical cancer cells and EOS remains unknown, and requires further investigation.

\section{Acknowledgements}

The present study was supported by the National Natural Science Foundation of China (grant nos. 91542108, 81471513 and 31600735), the Shanghai Rising-Star Program (grant no. 16QA1400800), the Development Fund of Shanghai Talents (grant no. 201557), the Program for Zhuoxue of Fudan University (grant no. 1326) and the Shanghai Natural Science Foundation (grant no. 17ZR1403200). 


\section{References}

1. Ferlay J, Shin HR, Bray F, Forman D, Mathers C and Parkin DM: Estimates of worldwide burden of cancer in 2008: GLOBOCAN 2008. Int J Cancer 127: 2893-2917, 2010.

2. de Freitas AC, Gurgel AP, Chagas BS, Coimbra EC and do Amaral CM: Susceptibility to cervical cancer: An overview. Gynecol Oncol 126: 304-311, 2012.

3. Wani $\mathrm{K}$ and Nair CK: Genetic alterations in cervical cancer. Indian J Exp Biol 41: 789-796, 2003.

4. Chen W, Zheng R, Baade PD, Zhang S, Zeng H, Bray F, Jemal A, Yu XQ and He J: Cancer statistics in China, 2015. CA Cancer J Clin 66: 115-132, 2016.

5. Jiang J, Yan M, Mehta JL and Hu C: Angiogenesis is a link between atherosclerosis and tumorigenesis: Role of LOX-1. Cardiovasc Drugs Ther 25: 461-468, 2011.

6. De Palma M, Biziato D and Petrova TV: Microenvironmental regulation of tumour angiogenesis. Nat Rev Cancer 17: 457-474, 2017.

7. Nyberg P, Salo T and Kalluri R: Tumor microenvironment and angiogenesis. Front Biosci 13: 6537-6553, 2008.

8. Folkman J and Shing Y: Angiogenesis. J Biol Chem 267: 10931-10934, 1992.

9. Chung AS and Ferrara N: Developmental and pathological angiogenesis. Annu Rev Cell Dev Biol 27: 563-584, 2011.

10. Fujimoto J, Sakaguchi H, Aoki I and Tamaya T: Clinical implications of expression of interleukin 8 related to angiogenesis in uterine cervical cancers. Cancer Res 60: 2632-2635, 2000.

11. López-Ocejo O, Viloria-Petit A, Bequet-Romero M, Mukhopadhyay D, Rak J and Kerbel RS: Oncogenes and tumor angiogenesis: The HPV-16 E6 oncoprotein activates the vascular endothelial growth factor (VEGF) gene promoter in a p53 independent manner. Oncogene 19: 4611-4620, 2000.

12. Liu YJ, Soumelis V, Watanabe N, Ito T, Wang YH, Malefyt Rde W, Omori M, Zhou B and Ziegler SF: TSLP: An epithelial cell cytokine that regulates $\mathrm{T}$ cell differentiation by conditioning dendritic cell maturation. Annu Rev Immunol 25: 193-219, 2007.

13. Sokol CL, Barton GM, Farr AG and Medzhitov R: A mechanism for the initiation of allergen-induced $\mathrm{T}$ helper type 2 responses. Nat Immunol 9: 310-318, 2008

14. Rochman Y and Leonard WJ: Thymic stromal lymphopoietin: A new cytokine in asthma. Curr Opin Pharmacol 8: 249-254, 2008.

15. Liu YJ: Thymic stromal lymphopoietin and OX40 ligand pathway in the initiation of dendritic cell-mediated allergic inflammation. J Allergy Clin Immunol 120: 238-246, 2007.

16. Park LS, Martin U, Garka K, Gliniak B, Di Santo JP, Muller W, Largaespada DA, Copeland NG, Jenkins NA, Farr AG, et al: Cloning of the murine thymic stromal lymphopoietin (TSLP) receptor: Formation of a functional heteromeric complex requires interleukin 7 receptor. J Exp Med 192: 659-670, 2000.

17. Reche PA, Soumelis V, Gorman DM, Clifford T, Liu Mr, Travis M, Zurawski SM, Johnston J, Liu YJ, Spits H, et al: Human thymic stromal lymphopoietin preferentially stimulates myeloid cells. J Immunol 167: 336-343, 2001.

18. Xie F, Meng YH, Liu LB, Chang KK, Li H, Li MQ and Li DJ: Cervical carcinoma cells stimulate the angiogenesis through TSLP promoting growth and activation of vascular endothelial cells. Am J Reprod Immunol 70: 69-79, 2013.

19. Xie F, Liu LB, Shang WQ, Chang KK, Meng YH, Mei J, Yu JJ, $\mathrm{Li}$ DJ and Li MQ: The infiltration and functional regulation of eosinophils induced by TSLP promote the proliferation of cervical cancer cell. Cancer Lett 364: 106-117, 2015.

20. Davis BP and Rothenberg ME: Eosinophils and cancer. Cancer Immunol Res 2: 1-8, 2014.

21. Facciabene A, Peng X, Hagemann IS, Balint K, Barchetti A, Wang LP, Gimotty PA, Gilks CB, Lal P, Zhang L and Coukos G: Tumour hypoxia promotes tolerance and angiogenesis via CCL28 and T(reg) cells. Nature 475: 226-230, 2011.
22. Cormier SA, Taranova AG, Bedient C, Nguyen T, Protheroe C, Pero R, Dimina D, Ochkur SI, O'Neill K, Colbert D, et al: Pivotal advance: Eosinophil infiltration of solid tumors is an early and persistent inflammatory host response. J Leukoc Biol 79 : 1131-1139, 2006

23. Ayhan A, Altintaş A, Tuncer ZS, Küçükali T and Yüce K: Prognostic value of mitotic activity, eosinophilic and inflammatory reaction in stage I cancer of the uterine cervix. Eur J Surg Oncol 18: 264-266, 1992.

24. Lotfi R, Lee JJ and Lotze MT: Eosinophilic granulocytes and damage-associated molecular pattern molecules (DAMPs): Role in the inflammatory response within tumors. J Immunother 30: 16-28, 2007.

25. Stone KD, Prussin C and Metcalfe DD: IgE, mast cells, basophils, and eosinophils. J Allergy Clin Immunol 125 (2 Suppl 2): S73-S80, 2010.

26. Pretlow TP, Keith EF, Cryar AK, Bartolucci AA, Pitts AM, Pretlow TG II, Kimball PM and Boohaker EA: Eosinophil infiltration of human colonic carcinomas as a prognostic indicator. Cancer Res 43: 2997-3000, 1983.

27. Caruso RA, Parisi A, Quattrocchi E, Scardigno M, Branca G Parisi C, Lucianò R, Paparo D and Fedele F: Ultrastructural descriptions of heterotypic aggregation between eosinophils and tumor cells in human gastric carcinomas. Ultrastruct Pathol 35 145-149, 2011.

28. Horiuchi K, Mishima K, Ohsawa M, Sugimura M and Aozasa K Prognostic factors for well-differentiated squamous cell carcinoma in the oral cavity with emphasis on immunohistochemical evaluation. J Surg Oncol 53: 92-96, 1993.

29. Hanahan D and Folkman J: Patterns and emerging mechanisms of the angiogenic switch during tumorigenesis. Cell 86: 353-364, 1996.

30. Carmeliet P: Angiogenesis in life, disease and medicine. Nature 438: 932-936, 2005.

31. Folkman J and Kalluri R: Cancer without disease. Nature 427 787, 2004.

32. Ruhrberg C: Growing and shaping the vascular tree: Multiple roles for VEGF. Bioessays 25: 1052-1060, 2003.

33. Sulpice E, Ding S, Muscatelli-Groux B, Bergé M, Han ZC, Plouet J, Tobelem G and Merkulova-Rainon T: Cross-talk between the VEGF-A and HGF signalling pathways in endothelial cells. Biol Cell 101: 525-539, 2009.

34. Cross MJ and Claesson-Welsh L: FGF and VEGF function in angiogenesis: Signalling pathways, biological responses and therapeutic inhibition. Trends Pharmacol Sci 22: 201-207, 2001.

35. Puxeddu I, Alian A, Piliponsky AM, Ribatti D, Panet A and Levi-Schaffer F: Human peripheral blood eosinophils induce angiogenesis. Int J Biochem Cell Biol 37: 628-636, 2005.

36. Munitz A and Levi-Schaffer F: Eosinophils: 'New' roles for 'old' cells. Allergy 59: 268-275, 2004.

37. Salcedo R, Young HA, Ponce ML, Ward JM, Kleinman HK, Murphy WJ and Oppenheim JJ: Eotaxin (CCL11) induces in vivo angiogenic responses by human $\mathrm{CCR} 3^{+}$endothelial cells. J Immunol 166: 7571-7578, 2001

38. Nissim Ben Efraim AH,Eliashar R and Levi-Schaffer F: Hypoxia modulates human eosinophil function. Clin Mol Allergy 8: 10, 2010.

39. Porter LM, Cowburn AS, Farahi N, Deighton J, Farrow SN, Fiddler CA, Juss JK, Condliffe AM and Chilvers ER: Hypoxia causes IL-8 secretion, Charcot Leyden crystal formation, and suppression of corticosteroid-induced apoptosis in human eosinophils. Clin Exp Allergy 47: 770-784, 2017.

40. Temkin V, Aingorn H, Puxeddu I, Goldshmidt O, Zcharia E, Gleich GJ, Vlodavsky I and Levi-Schaffer F: Eosinophil major basic protein: First identified natural heparanase-inhibiting protein. J Allergy Clin Immunol 113: 703-709, 2004. 